\title{
Meteorological Risk Assessment for Ships with Fuzzy Logic Designer
}

\author{
Ismail Karaca, Ridvan Saracoglu, Omer Soner
}

\begin{abstract}
Fuzzy Logic, an advanced method to support decision-making, is used by various scientists in many disciplines. Fuzzy programming is a product of fuzzy logic, fuzzy rules, and implication. In marine science, fuzzy programming for ships is dramatically increasing together with autonomous ship studies. In this paper, a program to support the decision-making process for ship navigation has been designed. The program is produced in fuzzy logic and rules, by taking the marine accidents and expert opinions into account. After the program was designed, the program was tested by 46 ship accidents reported by the Transportation Safety Investigation Center of Turkey. Wind speed, sea condition, visibility, day/night ratio have been used as input data. They have been converted into a risk factor within the Fuzzy Logic Designer application and fuzzy rules set by marine experts. Finally, the expert's meteorological risk factor for each accident is compared with the program's risk factor, and the error rate was calculated. The main objective of this study is to improve the navigational safety of ships, by using the advance decision support model. According to the study result, fuzzy programming is a robust model that supports safe navigation.
\end{abstract}

Keywords-Calculation of risk factor, fuzzy logic, fuzzy programming for ship, safe navigation of ships.

\section{INTRODUCTION}

$\mathrm{M}$ ARITIME transportation has been increasing day by day, because it is cheaper and its carrying capacities are higher than other forms of transportation. Besides, it supports more than $90 \%$ of international trade volumes in these days, and it is one of the oldest forms of interaction in the world [1]. These and similar conditions made the industrialization of maritime transport possible, so the maritime industry was formed. Maritime freight transport and auxiliary services, like agency, storage, are developing and evolving momently, form the maritime industry. Also, the maritime industry is affected by many fields such as tourism, economy, environment, engineering, and it has a significant role in the scientific world. Moreover, some countries even consider the development of the maritime industry as the first step in the development of their country [2]-[4]. All these prove the importance of the maritime industry, and they show the value of every study done on this subject.

Maritime industry is a place where organizations cooperate with their competitors and share common goals and mutual benefits, and it is becoming globalized [5]. In order to connect

İ. K. and Ö. S. are with the Faculty of Maritime, Van Yüzüncü Y1l University, Van, 65090 Turkey (phone: +90 4324445065 / 25613; e-mail: ismailkaraca@yyu.edu.tr, soneromer023@gmail.com).

R.S is with the Faculty of Engineering, Van Yüzüncü Yıl University, Van, 65090 Turkey (e-mail: ridvansaracoglu@yyu.edu.tr). with the advancement in technological developments, sailors and scientists have tried to find solutions with technological discoveries for the problems in the maritime industry. Examples of this can be seen in all aspects of shipping. For instance, the number of marine accidents had decreased between 1979 and 2001, but it began to increase again in 2002. Then, it reached the second-highest level in 50 years, exceeding 2000 in 2008. Therefore, many studies are carried out in order to prevent accidents and to make maritime affairs safer in the maritime industry that has become more technological in the recent half-century [6]. However, accident data analysis and risk analysis/safety assessment, the trendiest research topics related to marine accidents, are more significant topics than others [6].

Accident data analysis and risk analysis/safety assessment, are the topics of paper about marine science [7]. Scientists use different scientific methods to prevent damages, and losses that may cause accidents. Bayesian classification, classification trees, combining classifiers that are subtopics of machine learning classification, fuzzy logic, and its derivatives that are mathematical approaches, and other statistical and probabilistic models were used for this purpose, and continue to be used. Fuzzy logic and its derivatives are the popular method of marine science for the safety of navigation. Many studies used fuzzy logic, especially when it comes to avoiding a collision. Meteorological risk assessment is neglected in those studies [8]-[11]. The fuzzy logic-based approach is convenient to make a ship-bridge collision alert system. The paper aims to prevent ship-bridge collision unlike our study [12]. The meteorological changes such as sea condition, wind condition, vision, and day/night have been neglected in some papers [13]-[15]. Maritime risk assessment including a meteorological risk assessment has been made, but meteorological risk assessment has not been studied in detail: membership functions were neglected, rules are not enough, relationships are not disclosed in some papers [16], [17]. There is a comprehensive study in this paper considering all those.

The important topics in solving the problem are to define the problem correctly and to choose the right model to solve this problem. In this study, we aim to perform the meteorological risk assessment of the ships to increase the safety of navigation. The problem of this study is the absence of a complete and accurate meteorological risk assessment to increase the safety of ships. The research method tool which was used in this study is the fuzzy logic application. Fuzzy Logic Designer, application of MATLAB program, was used to apply this method. The method with details is given in 
Section II. Moreover, the program created in this study was applied to real accident data. The findings are given in section II $C$.

\section{II.METHODOLOGY}

In this study, meteorological risk assessment is based on fuzzy logic.

\section{A. Fuzzy Logic}

In daily conversations, people use adjectives like, good, bad, long, short, new, old, and so on. In these communications, adjectives are sometimes insufficient to express our thoughts. Also they use adverbs of degree like, extremely, very, nearly, and so on. On the other hand, due to the increase of automatization and robotic technologies in engineering science, it was a requirement that the definition of these adjectives, and adverbs and explanations of the relationship between them must be clear. As a result, the term "fuzzy set" was invented to meet the requirement in 1965. Recently, these sets have evolved into fuzzy logic. Fuzzy sets and relationships between them form the basis of fuzzy logic [18].

Fuzzy sets are a unique method invented to express semantic uncertainty in the human tongue. Also, they make it feasible scientifically to cope with subjectivity [19]. The theory of fuzzy sets includes fuzzy set connectives (complementation, intersection, and union), implication operators, arithmetic operations, and ranking of fuzzy numbers [20]. Fuzzy relation equations and rules could be defined as relationships between fuzzy sets. Fuzzy relations are fuzzy sets defined on universal sets which are Cartesian products. Composition of fuzzy relations (min-max composition, maxstar composition), types of fuzzy relations (Reflexive, Symmetric, max-min transitive so on), and fuzzy reasoning (If $<$ premise $>$, then $<$ consequence $>$ ) are subtopics of fuzzy relations [21].

In this study, Meteorological Risk Factor (MRF) for a ship was calculated based on fuzzy logic. Details of the MRF for ships calculated with the fuzzy application were explained in Section II $B$. This calculation based on fuzzy logic was applied to real accident data in Section II $C$.

\section{B. MRF for Ship}

In this paper, MRF was created by wind speed, sea condition, visibility; day/night ratio was calculated. The risk factor calculation program was prepared by using the fuzzy logic designer application of the MATLAB. In this section, details of the program are given.

There are four topics for meteorological inputs: Wind speed, sea condition, visibility, day and night ratio, and one output: risk factor, Fig. 1.

There are three fuzzy sets for wind speed (W): light air, breeze, the high wind, Fig. 2 . The range $0-12$ is determined by considering the Beaufort scale which is currently being used in ships.

There are three fuzzy sets for sea condition (S): calm, slight, high wave, Fig. 3. The range 0-9 is determined by considering the Beaufort scale which is currently being used in ships.

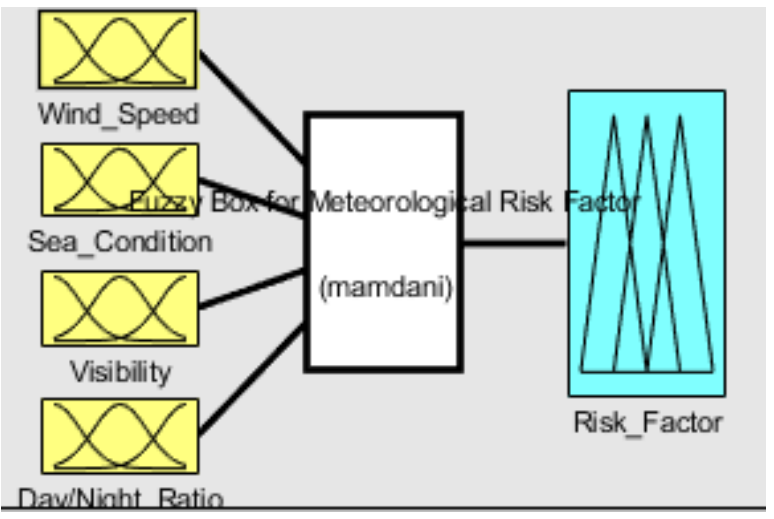

Fig. 1 Fuzzy logic based meteorological risk assessment model

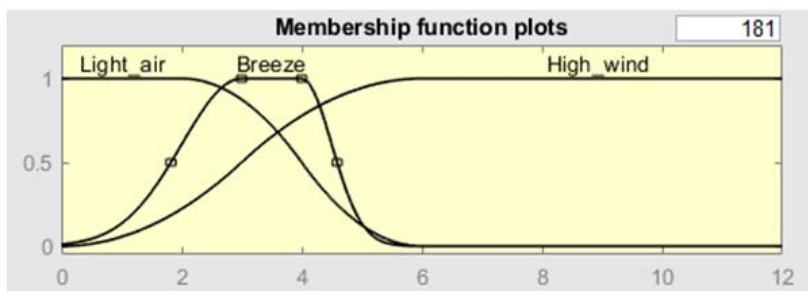

Fig. 2 Wind speed membership function for Meteorological risk assessment model

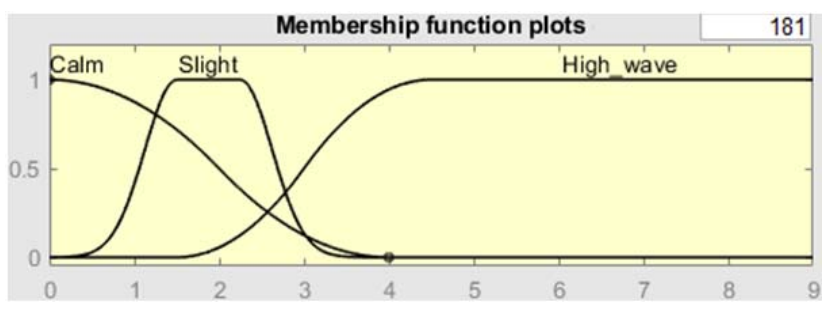

Fig. 3 Sea condition membership function for Meteorological risk assessment model

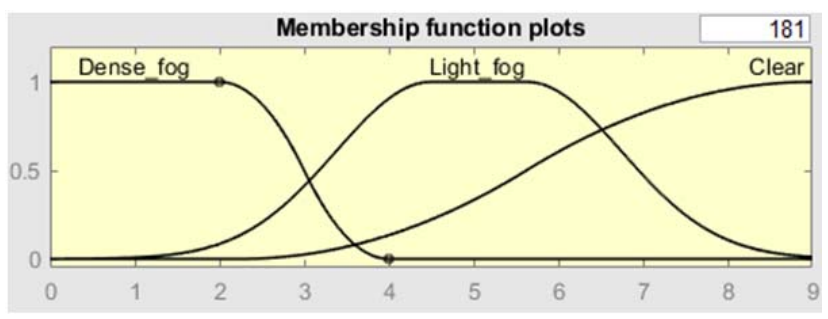

Fig. 4 Visibility membership function for Meteorological risk assessment model

There are three fuzzy sets for visibility (V): Dense fog, light fog, clear, Fig. 4. The range 0-9 is determined by considering the Visibility scale which is currently being used in ships.

There are three fuzzy sets for day and night ratio (D): Night, day, night 2 for values between 0-24, Fig. 5 .

There is a fuzzy set for meteorological output that risk factor: Little risk, medium risk, high risk for values between 0-100, Fig. 6.

81 rules have been determined considering each input set. 
This determination was made with experts, 1 of whom is a captain and 2 of which are the oceangoing officers on watch. As a result of this determination, 15 little risk, 42 medium risk, and 24 high risks were found. The relations based on these rules are shown in Fig. 7.

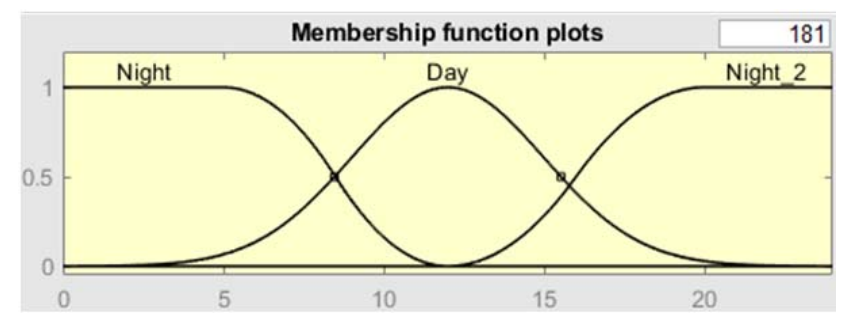

Fig. 5 Day or night ratio membership function for Meteorological risk assessment model

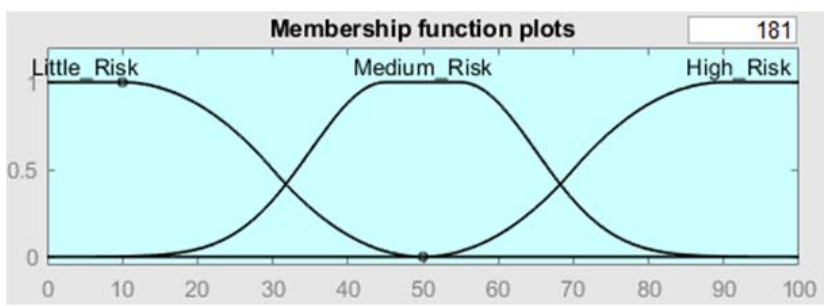

Fig. 6 MRF membership function for Meteorological risk assessment model

\begin{tabular}{|c|c|c|}
\hline And method & $\min$ & $\checkmark$ \\
\hline Or method & $\max$ & $\checkmark$ \\
\hline Implication & $\min$ & $\checkmark$ \\
\hline Aggregation & $\max$ & $\checkmark$ \\
\hline Defuzzification & centroid & $\checkmark$ \\
\hline
\end{tabular}

Fig. 7 MRF membership function for Meteorological risk assessment model

\section{C.Simulation of Meteorological Risk Assessment Model}

In this study, 46 marine accident data which were reported by the Transportation Safety Investigation Center of Turkey between 2009 and 2019 were examined. In order to use the accident data in the test of the MRF fuzzy program, which are the output of our research, wind speed, sea condition, visibility, day/night ratio, data of the accidents must be included in the accident reports. Since these data were found in 29 accidents, these 29 accidents were tested in this study. In order to test the program, first of all, expert's Meteorological Risk Factor (EMRF) was done by sharing accident wind speed, sea condition, visibility, and day/night ratio information with an expert, and assessing meteorological risk to be made by an expert. Afterwards, by entering the accident data into the prepared program, the Program Risk Factor (PRF) calculated by the program was found for each accident. PRF was compared with EMRF by using the value of RMSE and MAPE [22].
MAPE is 18,9, RMSE is 10,3 . These values are good for a machine learning program. However, other studies can be done to decrease these values. Therefore, this study would guide other studies.

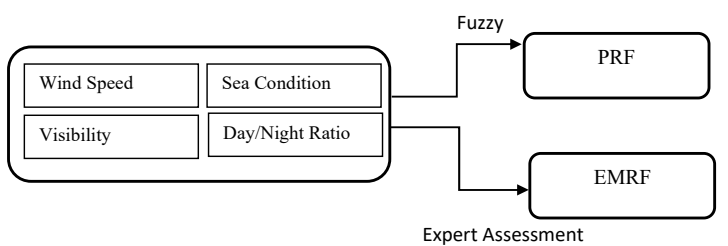

Fig. 8 The framework of Simulation Model

\section{RESUlts AND FINDINGS}

TABLE I

EXAMPLES OF ACCIDENT

\begin{tabular}{ccccccc}
\hline \hline $\mathrm{x}$ & $\mathrm{W}$ & $\mathrm{S}$ & $\mathrm{V}$ & $\mathrm{D}$ & PRF & EMRF \\
\hline 6 & 0 & 0 & 7 & 11 & 16,7 & 20 \\
8 & 3 & 2 & 7 & 5 & 49,5 & 50 \\
16 & 9 & 6 & 0 & 16 & 81,6 & 85 \\
25 & 1 & 0 & 7 & 11 & 20 & 20 \\
45 & 7 & 6 & 4 & 2 & 83,4 & 80 \\
\hline \hline
\end{tabular}

The examples subject to our research are given in Table I. When these are examined, it was seen that the sensitivity of the expert evaluation in the 6th and 25th accident decreases when the risk decreases, whereas the program risk gives sensitive values. In the 16th accident, it is possible to see that the program risk is very close to the expert opinion in cases that indicate high risk. Besides, in the 8th accident, PRF is almost the same value as EMRF. In the 45th accident information, it is seen that the program, like an expert, determines the risk factor by considering all the data and is sensitive in doing so.

With the advancement of technology, many developments have taken place in the maritime industry, as in many other fields. One of the main reasons for these developments is to prevent marine accidents. In this study, a meteorological risk assessment, which could be a decision support mechanism for the officer on the watch for ships, is made to prevent accidents. This decision support program is designed, based on fuzzy logic used in many scientific studies. This program, created as a result of this study, has been tested on marine accidents that have occurred. 5 results have been reached by realizing the stages of creating a program and testing the created program.

In this study, the applicability of fuzzy logic in the prevention of marine accidents has been proved. However, meteorological risk assessment is often neglected in the studies carried out to determine the danger of collision on the bridge. Unlike the others, in this paper, fuzzy logic was applied only in meteorological risk assessment for ships, and the suitability of the fuzzy-logic based meteorological risk assessment model for the ship was tested on real accidents. This study will form the basis for meteorological risk assessment in this regard. Therefore, it is proved by practice 
on real marine accidents that meteorological risk assessment based fuzzy logic is useful and easy. This paper proved the scientific effectiveness of fuzzy logic again and contributed to fuzzy logic in its applicability in different fields.

The program, which was formed as a result of the meteorological risk assessment detailed, can be used in the maritime sector as the output of the research. This program could also serve as a basis for automated bridge equipment in the maritime industry that goes to smart ships. The fact that the program created as a result of this study can be used as a decision support mechanism has proved the success of the fuzzy logic concept in grounding the decision support mechanism. As in this study, fuzzy logic is beneficial in studies performed by following all the rules of fuzzy logic. Fuzzy logic and its applications can form the basis for automation, and the studies done on machines to do every task which is done by humans.

In critical situations, people can make wrong decisions due to panic and other reasons, whereas a program based on fuzzylogic rules can always make the right decision and end up with correct results. In this study, a fuzzy logic application prepared in line with expert opinions proved to be equal with experts as a decision support mechanism. With a fuzzy logic or a similar scientific method, the creation of programs would be facilitated by examining situations such as meteorological risk assessment that can be ignored in emergencies. This study could form a basis in this regard.

The lack of a meteorological risk assessment system, which would be a decision support mechanism in the collision prevention movement, is a problem that was encountered in the test of the program we created. In this study, the program created to close this gap was tested with the expert assessment of the information on marine accidents. This deficiency is put forward thanks to this study. It is stated in this paper that the meteorological risk assessment performed can be a solution to this problem.

This study showed that it is an undeniable fact, that the meteorological factors affect marine accidents. However, it is wrong to say that the only cause of marine accidents is meteorological. To reduce the meteorological impact of marine accidents, a fuzzy-logic based decision support program, detailed in this study, was proposed. With this program, it is desired to fill the gap in the maritime industry that may cause an accident.

\section{FUNDING}

This research was funded by TK Foundation.

\section{REFERENCES}

[1] C. Ducruet, S. Cuyala, A. El Hosni, Maritime networks as systems of cities: The long-term interdependencies between global shipping flows and urban development (1890-2010), Journal of Transport Geography 66 (2018) 340-355.

[2] T.-O. Nævestad, K.V. Størkersen, A. Laiou, G. Yannis, Framework conditions of occupational safety: Comparing Norwegian maritime cargo and passenger transport, International Journal of Transportation Science and Technology 7(4) (2018) 291-307.

[3] S. Niavis, T. Papatheochari, T. Kyratsoulis, H. Coccossis, Revealing the potential of maritime transport for 'Blue Economy' in the Adriatic-
Ionian Region, Case Studies on Transport Policy 5(2) (2017) 380-388.

[4] P. Zhang, L. Drumm, The German Shipping Foundation: Has it been effective in maintaining maritime expertise in Germany?, Marine Policy (2020) 103871

[5] O. Ellingsen, K.E. Aasland, Digitalizing the maritime industry: A case study of technology acquisition and enabling advanced manufacturing technology, Journal of Engineering and Technology Management 54 (2019) 12-27.

[6] M. Luo, S.-H. Shin, Half-century research developments in maritime accidents: Future directions, Accident Analysis \& Prevention 123 (2019) 448-460.

[7] A. Toffoli, J.M. Lefevre, E. Bitner-Gregersen, J. Monbaliu, Towards the identification of warning criteria: Analysis of a ship accident database, Applied Ocean Research 27(6) (2005) 281-291.

[8] T. Brcko, J. Svetak, Fuzzy Reasoning as a Base for Collision Avoidance Decision Support System, Promet-Traffic \& Transportation 25(6) (2013) 555-564.

[9] L.P. Perera, J.P. Carvalho, C.G. Soares, Fuzzy-logic based parallel collisions avoidance decision formulation for an Ocean Navigational System, IFAC Proceedings Volumes 43(20) (2010) 260-265.

[10] C.T. Cai, C.S. Yang, Q.D. Zhu, Y.H. Liang, Ieee, A fuzzy-based collision avoidance approach for multi-robot systems, Ieee, New York, 2007.

[11] N.A. Sedova, V.A. Sedov, R.I. Bazhenov, The Neural-Fuzzy Approach as a Way of Preventing a Maritime Vessel Accident in a Heavy Traffic Zone, Advances in Fuzzy Systems (2018) 8.

[12] B. Wu, T.L. Yip, X. Yan, C. Guedes Soares, Fuzzy logic based approach for ship-bridge collision alert system, Ocean Engineering 187 (2019) 106152.

[13] F. Goerlandt, J. Montewka, V. Kuzmin, P. Kujala, A risk-informed ship collision alert system: Framework and application, Saf. Sci. 77 (2015) 182-204.

[14] V.S. Nguyen, N.K. Im, Automatic Ship Berthing Based on Fuzzy Logic, International Journal of Fuzzy Logic and Intelligent Systems 19(3) (2019) 163-171.

[15] S.L. Kao, K.T. Lee, K.Y. Chang, M.D. Ko, A fuzzy logic method for collision avoidance in Vessel Traffic Service, Journal of Navigation 60(1) (2007) 17-31

[16] J.-F. Balmat, F. Lafont, R. Maifret, N. Pessel, MAritime RISk Assessment (MARISA), a fuzzy approach to define an individual ship risk factor, Ocean Engineering 36(15) (2009) 1278-1286.

[17] J.-F. Balmat, F. Lafont, R. Maifret, N. Pessel, A decision-making system to maritime risk assessment, Ocean Engineering 38(1) (2011) 171-176.

[18] L.A. Zadeh, Fuzzy logic - a personal perspective, Fuzzy Sets and Systems 281 (2015) 4-20.

[19] CHAPTER 1 - Introduction to Fuzzy Systems, in: T. Terano, K. Asai, M. Sugeno (Eds.), Applied Fuzzy Systems, Academic Press1989, pp. 1-

[20] Chapter 2 - Basic Notions in Fuzzy Set Theory, in: D. Dubois, H. Prade, R.R. Yager (Eds.), Readings in Fuzzy Sets for Intelligent Systems, Morgan Kaufmann1993, pp. 21-26.

[21] A.M. Ibrahim, Chapter 3 - Fuzzy relations, in: A.M. Ibrahim (Ed.), Fuzzy Logic for Embedded Systems Applications, Newnes, Burlington, 2004, pp. 53-67.

[22] L.A. Bacci, L.G. Mello, T. Incerti, A. Paulo de Paiva, P.P. Balestrassi, Optimization of combined time series methods to forecast the demand for coffee in Brazil: A new approach using Normal Boundary Intersection coupled with mixture designs of experiments and rotated factor scores, International Journal of Production Economics 212 (2019) 186-211.

\section{Creative Commons Attribution License 4.0 (Attribution 4.0 International, CC BY 4.0)}

This article is published under the terms of the Creative Commons Attribution License 4.0 https://creativecommons.org/licenses/by/4.0/deed.en_US 